\title{
Resistance of interleukin-6 to the extracellular inhibitory environment promotes axonal regeneration and functional recovery following spinal cord injury
}

\author{
GANG YANG and WEN-YUAN TANG
}

Department of Neurosurgery, The First Affiliated Hospital of Chongqing Medical University, Chongqing 400016, P.R. China

Received June 14, 2016; Accepted January 3, 2017

DOI: $10.3892 /$ ijmm.2017.2848

\begin{abstract}
Interleukin-6 (IL)-6 was originally discovered as a factor that contributes to the secondary pathological and inflammatory response in the central nervous system (CNS) following injury. However, accumulating evidence suggests that IL-6 is also involved in functional and structural recovery following CNS injury by promoting axonal sprouting. This suggests a potential dual role of IL-6 in CNS injury. However, the definitive function of IL-6 in neural injury and the corresponding underlying mechanisms are still topics of controversy. The present study was carried out to examine the potential function of IL-6 in resistance to neurite growth-inhibitory effects via regulation of the expression of growth associated protein-43 (GAP-43), myelin-associated neurite outgrowth inhibitor (Nogo-A) and its receptor $(\mathrm{NgR})$. Rat dorsal root ganglion (DRG) neurons cultured in an inhibitory microenvironment mimicking injured CNS were used to investigate the effects of IL-6 on the outgrowth of neuronal processes. Additionally, IL-6 was subarachnoidally injected into rats to establish a spinal cord injury (SCI) model, and the neurobehavioral manifestations and neural morphology were subsequently evaluated to determine the effect of IL-6 on neural regeneration. Finally, the potential molecular mechanisms of IL-6-mediated regeneration and functional recovery following CNS injury are discussed. The results of the present study demonstrated that the in vitro administration of IL-6 enhanced the neurite outgrowth of DRG neurons in a dose-dependent manner via resisting the inhibitory function of myelin proteins. All doses of the IL-6 subarachnoid injection improved the Basso, Beattie and Bresnahan scores following SCI, with a large number of axonal sproutings observed at the spinal lesion site, and several sprouting fibers being elongated and bypassing the lesion and entered the caudal spinal cord. Additionally, a significantly increased density
\end{abstract}

Correspondence to: Professor Wen-Yuan Tang, Department of Neurosurgery, The First Affiliated Hospital of Chongqing Medical University, 1 Youyi Road, Chongqing 400016, P.R. China

E-mail: yg_angcq@163.com

Key words: interleukin-6, spinal cord injury, axonal regeneration area of diaminobenzidine-labeled neural fiber was observed in rats that received a subarachnoid injection of IL-6, and the rats exhibited increased expression of GAP-43 and decreased expression of Nogo-A. In conclusion, the results of the present study indicated that IL- 6 interferes with the inhibitory functions of myelin proteins by upregulating the expression of GAP-43 and simultaneously downregulating the expression of Nogo-A and $\mathrm{NgR}$ to promote axonal sprouting and functional recovery following SCI.

\section{Introduction}

The majority of neurons in the adult mammalian central nervous system (CNS) fail to spontaneously regenerate following injury, predominantly due to the presence of myelin-associated inhibitors and the development of glial scars that form an inhibitory environment for regeneration (1-5). Thus, elimination of inhibitory factors, blocking of inhibitory signaling pathways and increasing the intrinsic growth state of neurons are the strategies currently used to promote regeneration of CNS neurons.

Growth associated protein-43 (GAP-43) is a well-known specific marker of axonal regeneration predominantly localized at the growth cone and presynaptic terminals of developing axons. GAP-43 is involved in neuronal pathfinding and branching during development and regeneration, and aids the formation and regulation of synapses, which is crucial for synaptic plasticity. It is highly expressed following CNS injury to promote neural regeneration $(6,7)$. However, axonal regeneration is severely restricted by the inhibitory microenvironment formed by myelin-associated neurite outgrowth inhibitor (Nogo-A) and other components of the glial scar. Currently, Nogo-A and its receptor $(\mathrm{NgR})$ are regarded as crucial inhibitory factors for axonal regeneration following CNS injury $(8,9)$.

The cytokine interleukin-6 (IL)-6, is a major mediator of inflammation and IL-6 levels are elevated at varying degrees within the brain, blood and serum following CNS damage. It has been previously reported that the accumulation of IL-6 is involved in causing secondary damage following CNS injury and connective tissue scar formation (10-12). However, several previous studies have demonstrated that IL-6 is a highly versatile cytokine and exerts a beneficial effect on neural regeneration and functional recovery $(5-7,13)$. 
The aim of our present study was to provide evidence validating the neuroprotective and regeneration-enhancing effects of IL-6. The study initially demonstrated that IL-6 promoted regeneration of neurons and axons in cultured dissociated dorsal root ganglion (DRG) neurons and an establish rat spinal cord injury (SCI) model. Furthermore, the data indicated that the pro-regenerative effects of IL-6 are associated with the upregulation of GAP-43 and the downregulation Nogo-A and NgR.

\section{Materials and methods}

Materials. The following products were utilized in the present study: rabbit anti- $\beta$-III-tubulin polyclonal antibody (cat. no. 1967-1; Abcam, Cambridge, MA, USA); fluorescein isothiocyanate (FITC)-labeled goat anti-rabbit IgG (Beijing Zhongshan Jinqiao Biotechology Co., Ltd., Beijing, China); recombinant rat IL-6 (R\&D Systems, Inc., Minneapolis, MN, USA) biotinylated dextran amine (BDA)-10000 (cat. no. D1956; Molecular Probes, Thermo Fisher Scientific, Inc., Waltham, MA, USA); $10 \%$ BDA (pH 7.3) was prepared with $0.01 \mathrm{~mol} / 1$ phosphate-buffered saline (PBS); diaminobenzidine (DAB) powder (Sigma-Aldrich, St. Louis, MO, USA); $2.5 \%$ nickel ammonium sulfate-DAB was prepared with $0.82 \mathrm{~g}$ natrium aceticum, $2.5 \mathrm{~g}$ nickel ammonium sulfate and $100 \mathrm{ml} \mathrm{H}_{2} \mathrm{O}_{2}$; CNS myelin proteins (Sigma-Aldrich); Takara RNA PCR kit (Takara Biotechnology Co., Ltd., Dalian, China); rabbit anti-GAP-43 polyclonal antibody (cat. no. 1751-1; Abcam); rabbit anti-Nogo-A polyclonal antibody (cat. no. bs-0134R) and rabbit anti-NgR polyclonal antibody (cat. no. bs-0129R) (both from Bioss, Beijing, China) and mouse anti- $\beta$-actin monoclonal antibody (Boster Biotechnology Co., Ltd., Wuhan, China).

DRG culture. Adult male Wister rats were deeply anaesthetized with an intraperitoneal injection of $3.5 \%$ chloral hydrate $(10 \mathrm{ml} / \mathrm{kg})$. DRG neurons were harvested under a stereomicroscope and placed in a 10-ml tube on ice containing Ham's-F12 culture medium. Following removal of the attached roots and connective tissue capsules using forceps, DRG neurons were washed with F12 medium 3 times and centrifuged at $500 \mathrm{rpm}$ for $4 \mathrm{~min}$, then subsequently digested with $0.125 \%$ collagenase IV in an incubator for $45 \mathrm{~min}$ and with $0.25 \%$ collagenase IV for $15 \mathrm{~min}$. The neurons were washed with F12 medium following digestion, following which digestion was terminated with F12 solution containing $20 \%$ fetal calf serum (FCS). The cell suspension was centrifuged at $400 \mathrm{rpm}$ for $5 \mathrm{~min}$ following mechanical isolation of the cells in $\mathrm{N} 2$ medium. The supernatant was discarded and the cell pellet was resuspended in $2 \mathrm{ml} \mathrm{N} 2$ medium added with $15 \%$ bovine serum albumin (BSA) then centrifuged again at $900 \mathrm{rpm}$ for $10 \mathrm{~min}$. Cell debris was collected at the BSA/N2 interface and discarded with the supernatant. DRG neurons were again washed with $\mathrm{N} 2$ medium and centrifuged at $500 \mathrm{rpm}$ for $5 \mathrm{~min}$ and plated onto poly-L-lysine pre-coated culture dishes. In the myelin protein and IL-6 groups, culture wells were also pre-coated with myelin protein in addition to poly-L-lysine. After approximately $1 \mathrm{~h}$, cell adherence was detected and then sufficient N2 medium was added to the culture dish. Cultured DRG neurons were divided into: sham control, myelin protein and IL- 6 intervention groups. The IL-6 intervention group was further subdivided into 3 groups treated with either 50, 100 or $200 \mathrm{ng} / \mathrm{ml}$ IL-6. All experiments in each group were performed 3 times. After $48 \mathrm{~h}$ in culture, DRG neurons were fixed for immunostaining and mRNA extraction.

Identification of DRG neurons and evaluation of purity. The cultured DRG neurons were evaluated for purity by counting positive neurons demonstrated by the formation of neuronal processes under a microscope. Cell counting was performed in 5 random $\times 400$ microscopic fields/well, and the proportion of positive neurons to the total cell number in 3 wells was calculated to indicate the purity of the DRG neurons.

Immunocytochemistry. DRG neuronal suspensions were transferred onto poly-L-lysine pre-coated coverslips in 24-well plates $\left(1 \times 10^{5} \mathrm{DRG}\right.$ neurons/well). Following incubation, the cells were washed with $0.01 \mathrm{M}$ PBS, $3 \times 5$ min and fixed with $4 \%$ formaldehyde for $30 \mathrm{~min}$. The cells were then incubated with $0.4 \%$ Triton X-100 for 20 min and goat serum for $30 \mathrm{~min}$ to block non-specific protein binding. Subsequently, the cells were incubated overnight with the primary antibody (rabbit anti- $\beta$-III-tubulin polyclonal antibody; 0.01 M PBS was used in the sham control group) at $4^{\circ} \mathrm{C}$.

Following overnight incubation, the coverslips were washed with PBS (3x5 min) and incubated with FITC goat anti-rabbit IgG diluted 1:100 for $2 \mathrm{~h}$ at room temperature, and then the coverslips were washed again $(3 \times 5 \mathrm{~min})$ with $0.01 \mathrm{M}$ PBS. Finally, the coverslips were mounted onto slides with $50 \%$ glycerinum. The lengths of the neural processes in the 50 longest neurons were measured in 10 randomly selected areas from each coverslip using confocal laser scanning microscopy. The values are represented as the mean \pm standard error.

Treatment of animals. Pathogen-free Sprague-Dawley (SD) rats (6-week-old; 200-240 g body weight) were purchased from the Laboratory Animal Center of Chongqing Medical University (Chongqing, China) [certificate, SCXK (YU) 2007-0001]. The SD rats were maintained under optimal conditions for hygiene, temperature $\left(20 \pm 2^{\circ} \mathrm{C}\right)$ and photoperiods (12-h light:12-h dark), and were provided food and water ad libitum according to the Institutional Guidelines for the Care and Use of Laboratory Animals. All animal procedures were approved by the Ethics Committee of Chongqing Medical University.

Acute SCI model and subarachnoid injection. The rat SCI model was produced by a modification of the classic Allen's weight drop method. A $5 \mathrm{~g}$ metal bar with a $2.5-\mathrm{mm}$ diameter was dropped through a guidance glass tube from a height of $5 \mathrm{~cm}$ onto the exposed surface of the spinal cord to inflict acute SCI centering on the T9 vertebra. With the aid of the operating microscope, an $8-\mathrm{cm}$ polyethylene catheter was inserted at a $30^{\circ}$ angle through the foramen magnum, advanced $3 \mathrm{~cm}$ caudally to the spinal subarachnoid space according to a procedure described previously (14). IL-6 (10, 50 and $100 \mathrm{pmol} / \mathrm{kg} / \mathrm{day})$ and $5 \mathrm{ml}$ saline were administered daily through the implanted catheter separately using a microsyringe for 7 consecutive days in the IL-6 group and saline group, whereas the sham control group did not receive IL-6 or saline administration. 
Table I. Primers used for RT-PCR.

\begin{tabular}{|c|c|c|c|c|}
\hline Genes & Sense $\left(5^{\prime} \rightarrow 3^{\prime}\right)$ & Antisense $\left(5^{\prime} \rightarrow 3^{\prime}\right)$ & $\begin{array}{l}\text { Product size } \\
\text { (bp) }\end{array}$ & $\begin{array}{c}\text { GenBank } \\
\text { accession no. }\end{array}$ \\
\hline GAP-43 & aggccaaggagaaggatgatg & tagctttagcagcactttctg & 220 & NM_017195 \\
\hline $\mathrm{NgR}$ & ttctgcatggcaaccgtatcc & ttggcaaacaggtagagggtc & 157 & NM_053613 \\
\hline Nogo-A & cttcettctctatctcetctc & atggatttgttgccctctctg & 148 & NM_031831 \\
\hline GAPDH & gtctacatgttccagtatgac & ccaaagttgtcatggatgacc & 376 & NM_017008 \\
\hline
\end{tabular}

RT-PCR, reverse transcription-polymerase chain reaction; GAP-43, growth associated protein-43; NgR, Nogo-A receptor; Nogo-A, myelin-associated neurite outgrowth inhibitor; GAPDH, glyceraldehyde 3-phosphate dehydrogenase.

Behavioral testing. The lower limb function of rats was tested via Basso, Beattie and Bresnahan (BBB) scoring (15) prior to the operation and at day $1,3,5,7,10$ and 14 post-operation.

$B D A$ injection. Rats were randomly divided into 2 groups and received $(\mathrm{n}=5$ each) saline or treatment with IL-6. At day 14 following the establishment of the SCI model, the rats were anesthetized with $3.5 \%$ chloral hydrate $(10 \mathrm{ml} / \mathrm{kg}$, i.p.), and then placed on a stereotaxic apparatus, according to previously described methods with appropriate modifications (16). An incision was made along the midline of the scalp, the periosteum was cleared and the bregma was exposed. Points $(\mathrm{A}=-1.0 \mathrm{~mm}, \mathrm{R}=+1.0 \mathrm{~mm} ; \mathrm{A}=+4.0 \mathrm{~mm}, \mathrm{R}=+1.0 \mathrm{~mm}$; $\mathrm{A}=-1.0 \mathrm{~mm}, \mathrm{R}=+5.0 \mathrm{~mm} ; \mathrm{A}=+4.0 \mathrm{~mm}, \mathrm{R}=+5.0 \mathrm{~mm} ; \mathrm{A}$, indicates anterior to the bregma; $\mathrm{R}$, indicates right of the bregma) were marked centering on the bregma to locate the right sensorimotor cortex and a rectangular-shaped flap between the 4 points was removed and bone windows measuring $5 \times 4 \mathrm{~mm}$ were prepared. Multiple injections of BDA (molecular weight, 10,000; 10\% 0.1 M phosphate buffer; pH 7.3; Molecular Probes, Thermo Fisher Scientific, Inc.) through a $10 \mu 1$ microsyringe were performed at the right sensorimotor cortex at 5 points with depths of $2 \mathrm{~mm}$ and $1 \mathrm{~mm}$ separately per site. For each injection, $1 \mu \mathrm{l}$ of BDA solution was gradually delivered.

Antegrade tracing with BDA. At 3 weeks after the injection of BDA, the rats were anaesthetized with $3.5 \%$ chloral hydrate, the L8-L10 vertebrae (with measured intervals from $5 \mathrm{~mm}$ above to $5 \mathrm{~mm}$ below the lesion site) were removed and fixed in $4 \%$ formaldehyde at $4^{\circ} \mathrm{C}$ overnight, then transferred to a $30 \%$ sucrose solution and incubated at $4^{\circ} \mathrm{C}$ until the tissue was deposited. Transverse sections $(50-\mu \mathrm{m}$ thickness) were cut using a cryostat (Leica-1850; Leica Biosystems, Wetzlar, Germany) and incubated in Tris-buffered saline (TBS) solution $(0.05 \mathrm{M}$, $\mathrm{pH} 7.6$ ) with $0.3 \%$ Triton $\mathrm{X}-100$ at room temperature for $4 \mathrm{~h}$. The sections were washed with $0.05 \mathrm{M} \mathrm{TBS}(3 \times 5 \mathrm{~min})$ and then incubated in horseradish peroxidase (HRP)-labeled streptavidin (1:200) at $4^{\circ} \mathrm{C}$ overnight. The HRP-labeled streptavidin was removed, and the sections were washed with $0.05 \mathrm{M}$ TBS (3x5 min). After 5-10 min preincubation in $2.5 \%$ ammonium nickel sulfate and $0.035 \%$ DAB, $0.05 \mathrm{~mol} / 1 \mathrm{TBS}$ was used to terminate the reaction. The sections were then transferred to glass slides pre-coated with 3-aminopropyltriethoxysilane and dehydrated in an ascending ethanol gradient, deparaffinized with xylene and embedded in epoxy resin. Finally, images were captured using a fluorescence microscope.

Immunofluorescence for the detection of GAP-43. The procedures performed to detect GAP-43 by immunofluorescence were identical to the immunohistochemistry experiments. Rabbit anti-GAP-43 polyclonal antibody (1:300 dilution) was used as the primary antibody, and fluorescence intensity was quantified based on the mean value of 4-5 cells/field measured using Quant Report software and laser confocal microscopy.

Western blotting for GAP-43, Nogo-A and NgR. Briefly, total protein was extracted from DRG neurons at $48 \mathrm{~h}$ after culture and removal from injured spinal cord tissue. The protein concentration was determined by Bradford assay. Equivalent amounts of protein $(30 \mu \mathrm{g})$ from each sample were separated on $10 \%$ SDS-PAGE gels and transferred onto a polyvinylidene fluoride membrane (Sigma-Aldrich). The membrane was blocked with 5\% non-fat milk in TBS, incubated with a rabbit anti-GAP-43 polyclonal antibody (1:200), rabbit anti-Nogo-A polyclonal antibody (1:200), rabbit anti-NgR polyclonal antibody $(1: 200)$ and a mouse anti- $\beta$-actin monoclonal antibody $(1: 1,000)$ overnight at $4^{\circ} \mathrm{C}$, followed by incubation with corresponding HRP-conjugated secondary antibodies $(1: 2,000)$ overnight at $4^{\circ} \mathrm{C}$. Specific blots were developed using ECL-Plus chemiluminescence. The densitometric quantification of the bands was performed using Quantity One software (Bio-Rad Laboratories, Inc., Hercules, CA, USA). The results are expressed as the ratio of the expression of GAP-43, Nogo-A and NgR to $\beta$-actin.

Reverse transcription-polymerase chain reaction (RT-PCR). Total RNA was purified from the SCI DRG neurons after $48 \mathrm{~h}$ in culture. The primers for GAP-43, Nogo-A, NgR and glyceraldehyde 3-phosphate dehydrogenase (GAPDH) were designed according to the published cDNA sequences (Table I). PCR was performed under the following conditions: denaturation at $94^{\circ} \mathrm{C}$ for $2 \mathrm{~min} ; 29$ cycles of denaturation at $94^{\circ} \mathrm{C}$ for $30 \mathrm{sec}$, annealing at $53^{\circ} \mathrm{C}$ for $30 \mathrm{sec}$ and extension at $72^{\circ} \mathrm{C}$ for $1 \mathrm{~min}$; followed by a final extension at $72^{\circ} \mathrm{C}$ for $10 \mathrm{~min}$.

Statistical analysis. Data are presented as the means \pm 6 standard deviations. Data analyses were performed with SPSS 10.0 software (SPSS, Inc, Chicago, IL, USA). Differences were examined for statistical significance using one-way analysis of variance (ANOVA) for comparisons involving more 
A

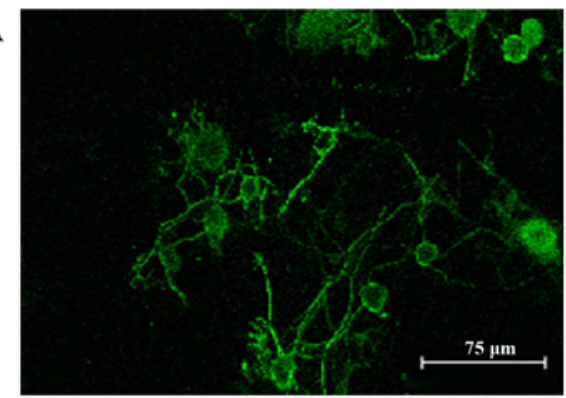

C

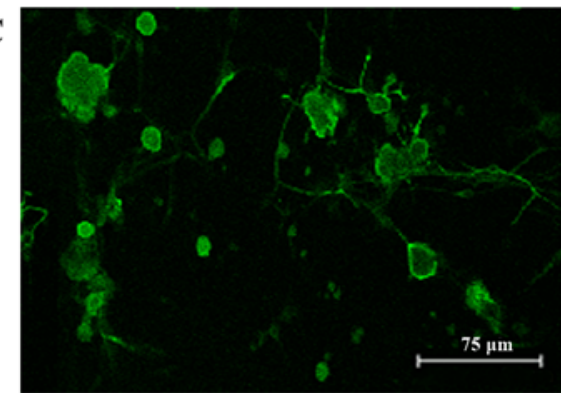

E

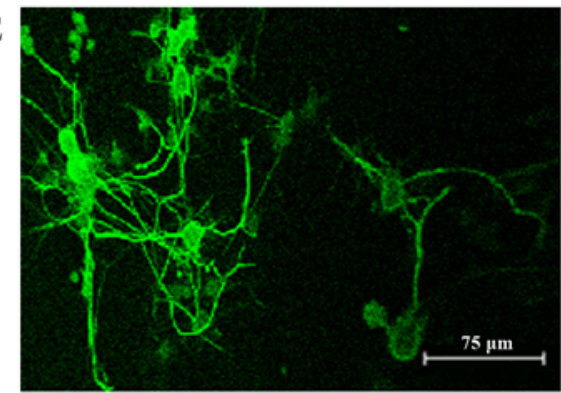

B

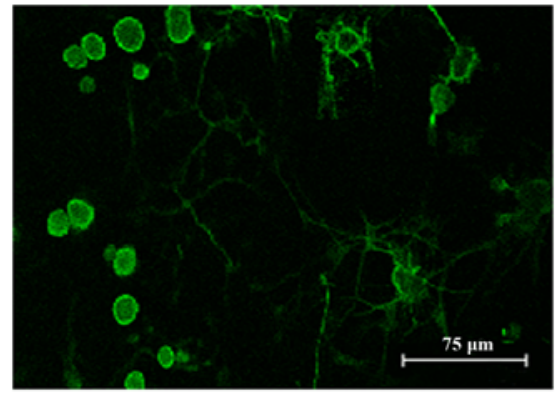

D

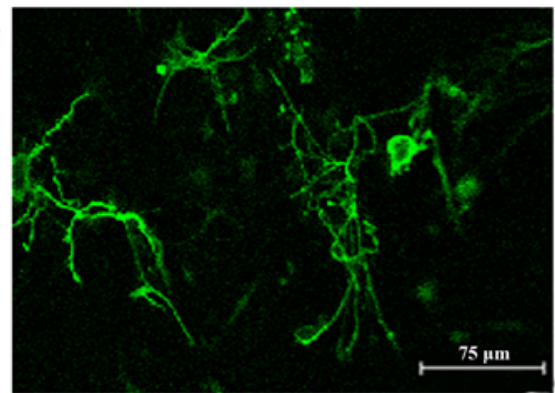

F

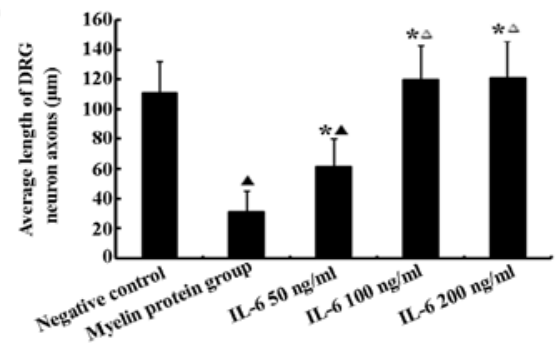

Figure 1. Effect of different concentrations of interleukin (IL)-6 and myelin proteins on the neurite outgrowth of adult rat dissociated dorsal root ganglion (DRG) neurons. (A-E) Representative images of neurite outgrowth (x400 magnification) in the (A) negative control group, (B) myelin protein group, (C) group exposed to IL-6 $50 \mathrm{ng} / \mathrm{ml}$, (D) group exposed to IL-6 $100 \mathrm{ng} / \mathrm{ml}$ and (E) group exposed to IL-6 $200 \mathrm{ng} / \mathrm{ml}$. (F) Analysis of the average length of DRG neuronal axons. Values are the means \pm standard deviation $(n=6)$. ${ }^{\wedge} \mathrm{P}<0.05$ vs. the sham control group; ${ }^{*} \mathrm{P}<0.05$, IL-6 treatment group vs. the myelin protein group; ${ }^{\Delta} \mathrm{P}<0.05$ comparison among various concentrations of IL-6.

than 2 groups and the Student's t-test for comparisons between 2 groups. $\mathrm{P}<0.05$ was considered to indicate a statistically significant difference.

\section{Results}

Identification and purity determination of DRG neurons. DRG neuronal identification was performed following $48 \mathrm{~h}$ in culture. Neurons exhibiting axonal sprouting under microscopic examination were considered as positive cells. The number of positive cells and the number of cells were counted in 5 random $x 400$ microscopic fields of 3 wells. The proportion of positive cells represented the purity of the DRG neurons. The purity of DRG was $>95 \%$ in the present study.

Effect of myelin proteins and IL-6 on the survival of DRG neurons in vitro. MTT assays indicated no significant difference in DRG neuronal survival among groups treated with the various concentrations of IL- 6 and the sham control $(\mathrm{P}>0.05)$, whereas myelin proteins significantly decreases DRG neuronal survival $(\mathrm{P}<0.05)$. Following $48 \mathrm{~h}$ in culture, DRG neurons in the myelin protein group exhibited significantly shorter neurites compared with the sham control and IL-6 groups $(\mathrm{P}<0.05)$. All of the IL-6 concentrations used promoted neurite outgrowth resulting in marked neurite extension compared with the myelin protein group. Thus, IL-6 reduced the inhibitory effect of myelin proteins $(\mathrm{P}<0.05)$. Furthermore, IL-6 treatment enhanced axonal regrowth in a dose-dependent manner demonstrating partial resistance to the effects of myelin proteins with $50 \mathrm{ng} / \mathrm{ml}$ IL- 6 and complete resistance in the 100 and $200 \mathrm{ng} / \mathrm{ml}$ groups. Neurites in the $50 \mathrm{ng} / \mathrm{ml} \mathrm{IL-6}$ group were significantly shorter compared with the 100 and $200 \mathrm{ng} / \mathrm{ml}$ groups $(\mathrm{P}<0.05)$. However, at a

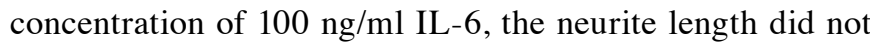
increase further as the concentration increased. There were no significant differences in neurite length among the 100 , $200 \mathrm{ng} / \mathrm{ml} \mathrm{IL-6}$ and the sham control group (P>0.05; Fig. 1).

IL-6 promotes functional recovery following SCI in vivo. The functional deficit in rats was measured at day 1 following SCI operation using the BBB scoring. Animals with a score $>1$ were excluded from further analyses. According to this criterion, 73 rats with experimentally induced SCI were randomly divided into 5 groups: sham operation, saline and IL-6 treatment with low-, moderate- and high-doses. Routine manually assisted urination was provided 2-3 times/day following the 
A

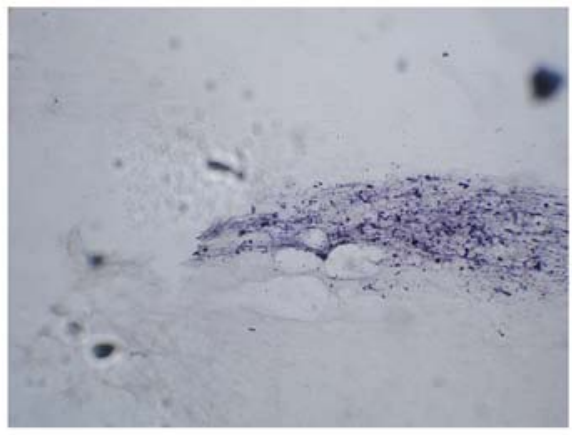

C

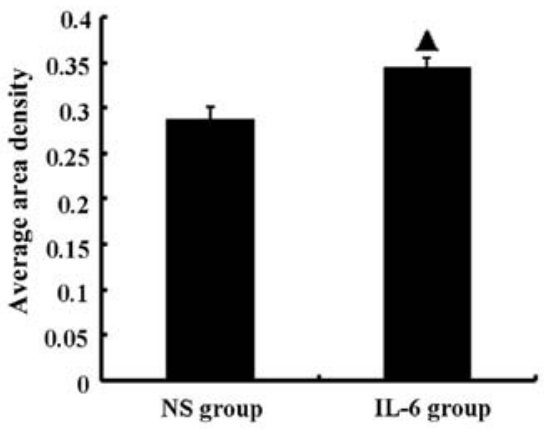

B

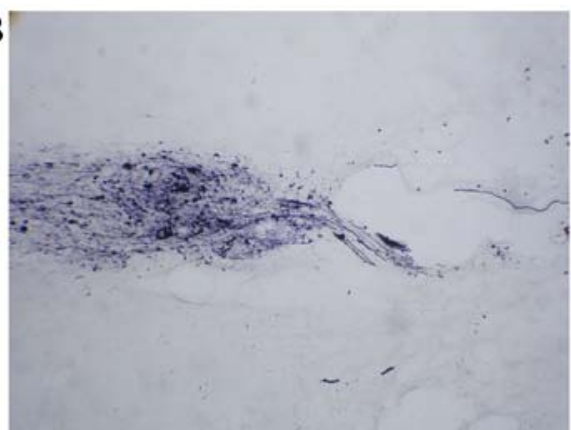

D

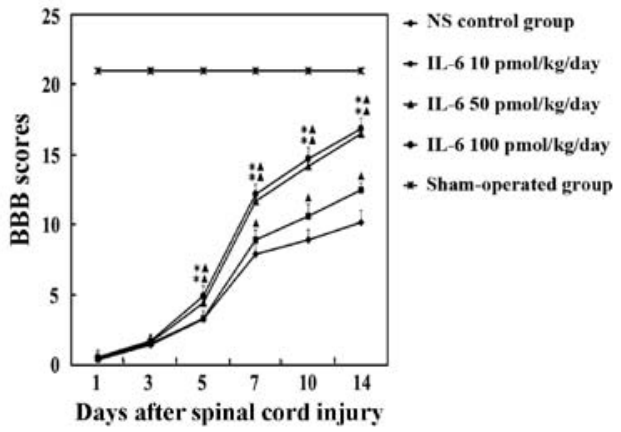

Figure 2. Comparison of average area density of diaminobenzidine (DAB)-positive fibers between the interleukin (IL)-6 group and saline group and Basso, Beattie and Bresnahan (BBB) scores following treatments with different concentrations of IL- 6 at different time-points. (A and B) Representative images of DAB-positive fibers (x400 magnification) in the (A) NS group and (B) IL-6 group. (C) Analysis of average area density of DAB-positive fibers. Values are presented as the means \pm standard deviation $(\mu \mathrm{m})(\mathrm{n}=6) .{ }^{\wedge} \mathrm{P}<0.05$ vs. the NS group; (D) ${ }^{\wedge} \mathrm{P}<0.05$ vs. the saline group; ${ }^{*} \mathrm{P}<0.05$ vs. the $10 \mathrm{pmol} / \mathrm{kg} / \mathrm{day}$ IL- 6 treated group.

operation until the recovery of voluntary urination 7-10 days later. Due to difficulty in urination assistance, 3 rats died from bladder rupture; thus, 72 rats were finally included in the BBB scoring analysis with 14 rats in each group.

BBB scores of the sham operation group were significantly different compared with SCI rats at all time-points investigated $(\mathrm{P}<0.05)$. Rats treated with the low-dose of IL-6 exhibited gradually increasing BBB scores from day 7 post-surgery and were consistently increased compared with the saline group during observation $(\mathrm{P}<0.05)$. In the groups that received moderate- and high-dose IL-6, BBB scores began to increase from day 5 post-surgery and were significantly higher compared with the saline and low-dose IL-6 groups ( $<<0.05$; Fig. 2D).

Anterograde tracing of corticospinal tract (CST) axons by $B D A$ indicates that $I L-6$ enhances axonal regeneration. Hematuria was resolved post-operatively in 8 out of 10 rats and disappeared within 4 days. Routine manually assisted urination was performed 2-3 times/day post-surgery until the recovery of voluntary urination after 7-10 days.

Rats were suspended by lifting of the tails at $2 \mathrm{~h}$ after BDA administration. When flexion and arm holding were observed in the left upper limbs and disappeared 3-5 h later, tracing to the right motor cortex was considered to have been successful.

In the saline group, the damaged segment of the spinal cord exhibited CTS interruption, axon retraction and an absence of growth cones at the rostral end, and few BDA-labeled fibers were observed to have assembled and grown through the lesion to reach the segment distal to the lesion center. Whereas in the IL-6 treatment group, very robust growth cone formation and aggregation of BDA-labeled fibers were observed, and several BDA-labeled axons were observed at the caudal end of the lesion (Fig. 2A and B).

Furthermore, pathological image analysis (CM-2000B; Beijing, China) demonstrated that the density of BDA-labeled axons was significantly increased in the IL-6 treatment group compared with the saline group. The mean area density values were $0.344 \pm 0.011$ and $0.288 \pm 0.013$, respectively $(\mathrm{P}<0.05$; Fig. 2C).

\section{IL-6 upregulates the expression of GAP-43 and downregu-} lates the expression of Nogo-A and $N g R$ in dissociated DRG neurons and SCI tissue. Semi-quantitative analyses of PCR bands were performed using the Quantity One software analysis system and the results were normalized to the optical density of the reference gene bands. The isolated DRG neurons treated with low-dose IL-6 demonstrated significantly higher expression of GAP-43 mRNA and lower expression of Nogo-A and $\mathrm{NgR}$ mRNA compared with the control group $(\mathrm{P}<0.05)$. Furthermore, compared with the control and low-dose IL-6 groups, the moderate- and high-dose IL- 6 groups exhibited a significantly higher level of GAP-43 mRNA and lower levels of Nogo-A and NgR mRNA $(\mathrm{P}<0.05)$. However, there was no significant difference between mRNA levels in the moderate- and high-dose IL-6 groups ( $\mathrm{P}>0.05$; Fig. 3A).

The mRNA expression of GAP-43 was increased in groups administrated with various doses of IL-6 and saline compared with the sham control group. Furthermore, the GAP-43 level was significantly increased in the IL-6 treatment group compared with the saline group $(\mathrm{P}<0.05)$. Additionally, 
A

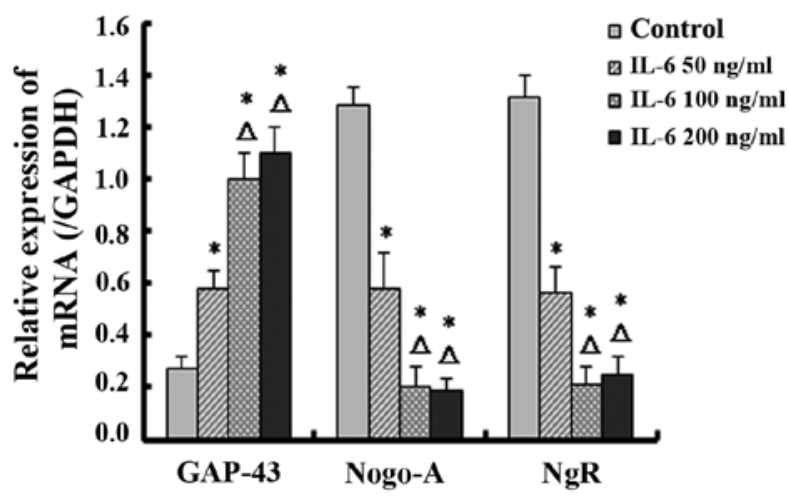

B

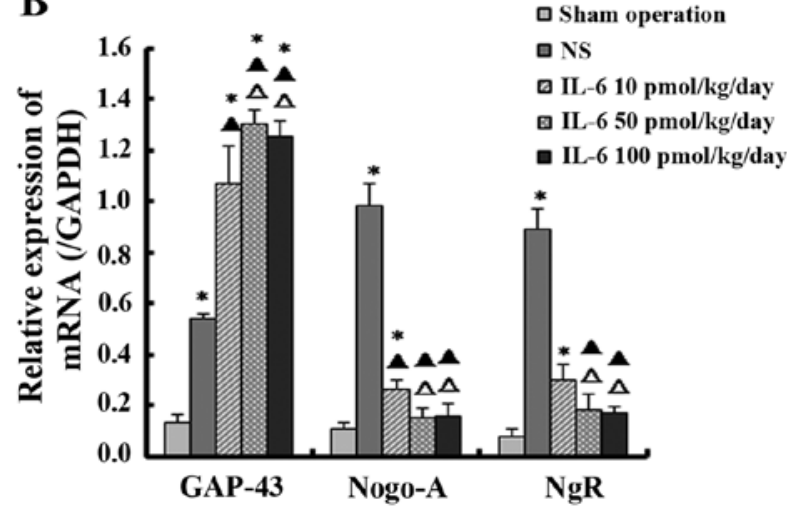

Figure 3. mRNA expression of growth associated protein-43 (GAP-43), myelin-associated neurite outgrowth inhibitor (Nogo-A) and its receptor (NgR) in the different (A) dorsal root ganglion (DRG) and (B) spinal cord groups. (A) ${ }^{*} \mathrm{P}<0.05$ vs. the control group; ${ }^{*} \mathrm{P}<0.05$ vs. the low-dose interleukin (IL)-6 group. (B) ${ }^{*} \mathrm{P}<0.05$ vs. the sham operation group; ${ }^{\wedge} \mathrm{P}<0.05$ vs. the saline group; ${ }^{\Delta} \mathrm{P}<0.05$ vs. the low-dose IL- 6 group.

A
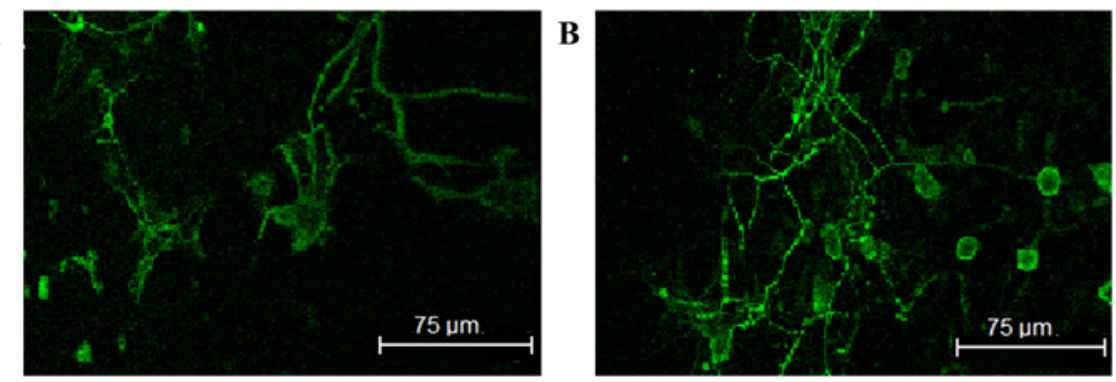

C
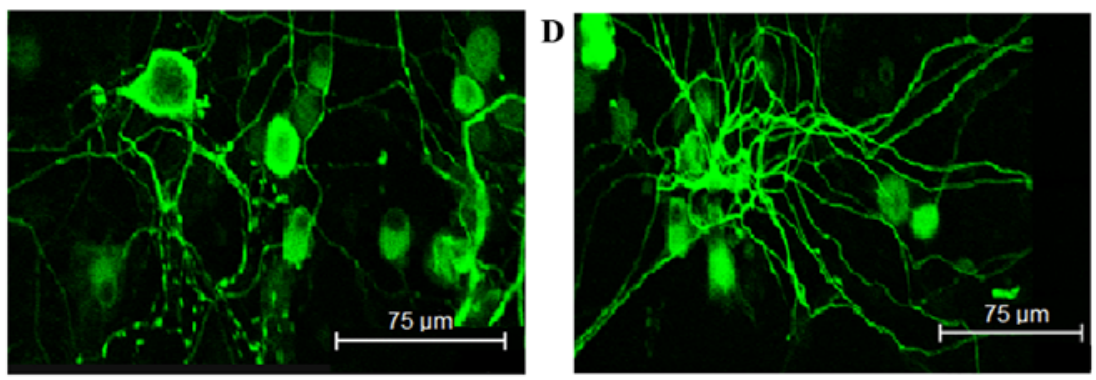

$\mathbf{E}$

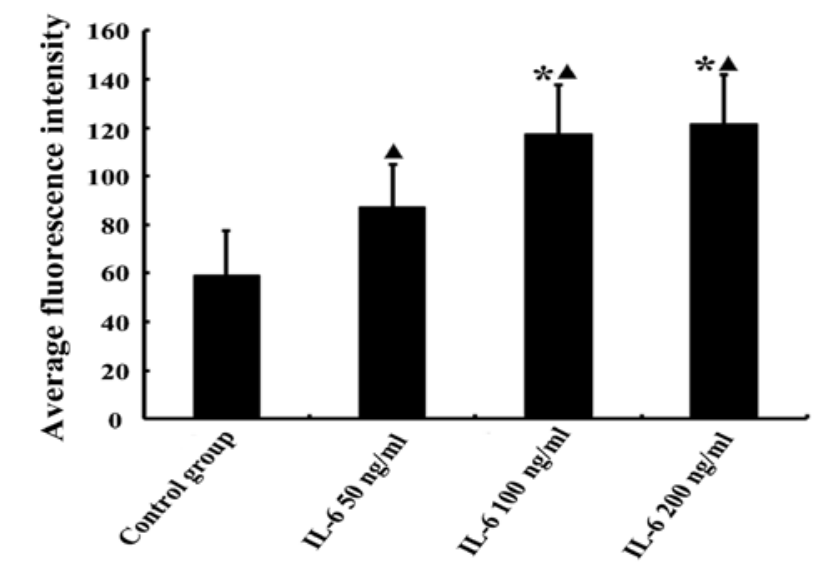

Figure 4. Intracellular growth associated protein-43 (GAP-43) immunofluorescent staining. (A-D) Alterations in green fluorescence intensity of dorsal root ganglion (DRG) neurons (x400 magnification) in the (A) control group, (B) interleukin (IL)-6 $50 \mathrm{ng} / \mathrm{ml} \mathrm{group}$, (C) IL-6 $100 \mathrm{ng} / \mathrm{ml} \mathrm{group}$ and (D) IL-6 $200 \mathrm{ng} / \mathrm{ml}$ group. (E) Analysis of average fluorescence intensity of DRG neuronal axons. Values are presented as the mean \pm standard deviation ( $\mathrm{n}=6$ ). ${ }^{\wedge} \mathrm{P}<0.05$ vs. the sham control group; ${ }^{*} \mathrm{P}<0.05$ vs. the low-dose IL-6 group.

among groups treated with IL-6, the level of GAP-43 mRNA in the moderate- and high-dose groups were significantly higher compared with the lose-dose group $(\mathrm{P}<0.05)$. However, the difference in GAP-43 levels between the moderate- and high-dose groups was not significant $(\mathrm{P}>0.05)$. Regarding Nogo-A and $\mathrm{NgR}$, compared with the sham group, the mRNA 
A

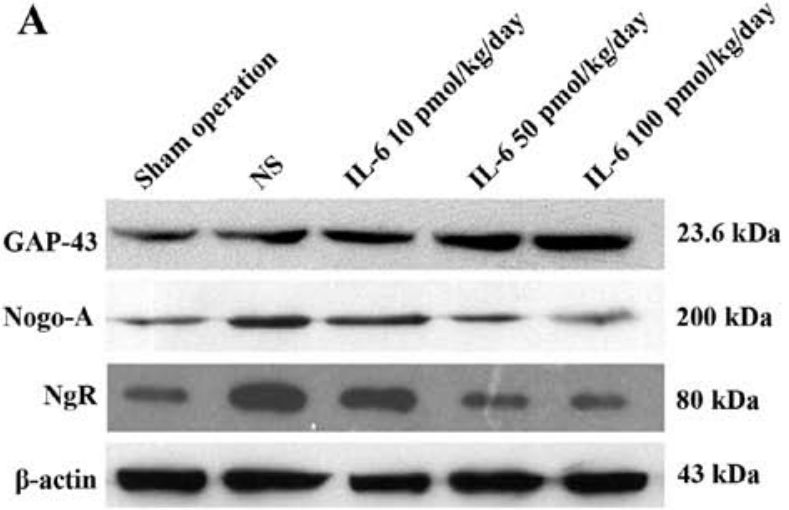

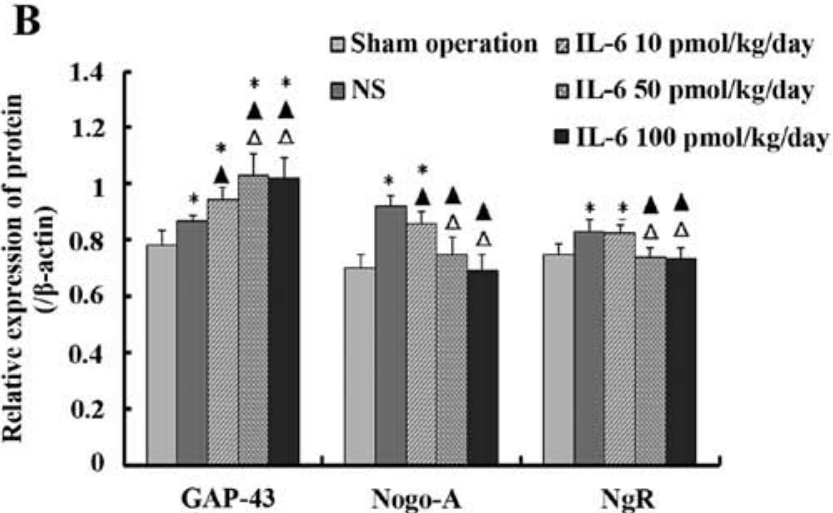

Figure 5. Protein expression levels of growth associated protein-43 (GAP-43), myelin-associated neurite outgrowth inhibitor (Nogo-A) and its receptor (NgR) following spinal cord injury (SCI). (A) Result of western blotting and (B) analysis of western blotting. Values are presented as the mean \pm standard deviation $(\mathrm{n}=6) .{ }^{*} \mathrm{P}<0.05$ vs. the sham control group; ${ }^{\wedge} \mathrm{P}<0.05$ vs. the saline group; ${ }^{\Delta} \mathrm{P}<0.05$ vs. the low-dose IL- 6 group.

level was highest in the saline group, and was decreased in the groups treated with IL-6 $(\mathrm{P}<0.05)$ compared with the saline group. The moderate- and high-dose IL- 6 significantly downregulated the expression of Nogo-A and NgR mRNA compared with the saline group to the level detected in the sham operation group $(\mathrm{P}>0.05)$. Additionally, there was no significant difference between the moderate- and high-dose group ( $\mathrm{P}>0.05$; Fig. 3B).

IL-6 upregulates the expression of GAP-43 in isolated DRG neurons. Green fluorescence represents the FITC-labeled target protein. The GAP-43 staining was more intense in the low-dose IL-6 group compared with the control group $(\mathrm{P}<0.05)$ and the intensity of staining was increased further in the moderate- and high-dose IL- 6 groups. There was no observable difference between the GAP-43 staining in the moderate- and high-dose groups ( $\mathrm{P}>0.05$; Fig. 4).

Effect of IL-6 on the expression of GAP-43, Nogo-A and NgR protein in injured spinal cord tissue. The levels of GAP-43, Nogo-A and $\mathrm{NgR}$ protein in injured spinal cord tissue were determined by western blotting. The results indicated that the expression level of GAP-43 protein was highest in the moderate- and high-dose IL- 6 groups, compared to the low-dose IL-6 and saline groups, and with the lowest level noted in the sham operation group. The difference between the moderate- and high-dose IL-6 group was not significant $(\mathrm{P}>0.05)$.

Compared with the sham operation group, the levels of Nogo-A and NgR protein were significantly higher in the saline and low-dose IL-6 groups $(\mathrm{P}<0.05)$, whereas the difference between the moderate- and high-dose IL-6 group was not significant $(\mathrm{P}>0.05)$. Furthermore, the levels of Nogo-A and $\mathrm{NgR}$ protein were highest in the saline group, than these levels in the low-dose IL-6 group, and lowest in the moderate- and high-dose IL- 6 groups. The difference between the moderate- and high-dose IL- 6 group was not significant ( $\mathrm{P}>0.05$; Fig. 5).

\section{Discussion}

Damage to the adult spinal cord often leads to persistent deficits due to the inability of mature axons to regenerate following injury. Mounting evidence suggests that the inhibitory local extracellular environment, formation of the glial scar and a decrease in the intrinsic regeneration capacity of mature neurons are the primary obstacles for axon regeneration. Various oligodendrocyte-derived myelin-associated neurogrowth inhibitory factors, including myelin-associated protein (MAP), Nogo and oligodendrocyte myelin glycoprotein (OMgp) are the main components of the extracellular inhibitory environment $(1-4,17)$.

Recently, an increasing number of studies have demonstrated that regeneration of a damaged adult axon is possible by either increasing the permissive cues or decreasing the non-permissive cues of the existing environment. This observation was followed by a series of significant results within animal spinal cord injury research. As a highly versatile cytokine, IL-6 has been previously reported to have both detrimental and beneficial effects in the nervous system. The detrimental effects are usually attributed to its pro-inflammatory actions contributing to inflammation following SCI. However, various studies have demonstrated that IL-6 is also involved in neuroprotection following SCI injury $(5-7,13,18)$. IL-6 is downstream of cyclic AMP, which has proven to be one of the most effective means of overcoming inhibition of axonal regeneration (18-22).

To mimic the inhibitory environment following SCI, myelin proteins were used as a culture substrate in the present study to observe the effect of IL-6 on the survival and neurite outgrowth of isolated DRG neurons. The in vitro results indicated that the adminstration of exogenous IL- 6 to the culture medium promoted neurite outgrowth in dissociated DRG neurons cultured on myelin proteins in a dose-dependent manner, exerting a partial effect at the concentration of $50 \mathrm{ng} / \mathrm{ml}$, and a complete effect at $100 \mathrm{ng} / \mathrm{ml}$. Enhancement of neuron regeneration ability was not observed as the concentration of IL-6 increased from 100 to $200 \mathrm{ng} / \mathrm{ml}$. Different doses of IL-6 exhibited varying effects on functional recovery following SCI. Faster functional recovery and higher BBB scores were observed in rats treated with moderate- and high-dose IL-6. This demonstrated that the myelin proteins inhibited neurite outgrowth of dissociated DRG neurons and that exogenous IL- 6 is beneficial for axonal regeneration by abrogating myelin protein-mediated inhibition of regeneration in vitro. The promoting effect of IL- 6 on axonal regeneration and spinal functional recovery was dose-dependent, which was 
in accordance with previous findings by Hakkoum et al (6). The mechanism of action of IL-6 in overcoming myelin inhibitors is via activation of the classic IL-6 trimeric receptor, resulting in activation of the Janus kinase/signal transducer and activator of transcription 3 (STAT3) and mitogen-activated protein kinase (MAPK) signaling cascade $(5,13,18,23,24)$. These different signaling pathways have been proposed to be important for the intracellular signaling mechanisms triggered by injury or associated with synaptic plasticity. For example, activation of STAT3 in retinal ganglion cells is essential for inflammatory stimulation, including IL-6-induced neuroprotection and axonal regeneration (5). Furthermore, the MAPK pathway is crucial for the stimulatory effects of neurotrophic factors, including nerve growth factor and glial-derived neurotrophic factor, on neurite outgrowth (25-27). Thus, IL-6 may activate these signaling cascades to promote regeneration in lesioned neurons (28).

BDAs are highly sensitive tools for anterograde and retrograde pathway tracing studies of the nervous system $(16,29)$. In the present study, microinjection of BDA was performed at multiple sites in the rat sensorimotor cortex to evaluate axonal sprouting following SCI, as impaired axon plasmic transport is followed by distal and partial proximal axon degeneration and fracture. The BDA tracing study demonstrated retraction and disruption of axons from the initial site the CST. In the saline-treated rats, no axons passed through the lesion site, whereas IL-6-treated rats exhibited a high-density of BDA-positive fibers in the sagittal section, with the compensatory spouts either directly growing through the lesion or circumventing the injury site to the distal segment of the spinal cord. These morphological results suggested that intrathecal administration of IL- 6 promoted compensatory sprouting of the CST following SCI.

To maintain the stable and complex state in the mature nervous system, the regeneration and plasticity of adult neurons are restricted. There is, however, evidence from animal studies demonstrating that axonal elongation and partial neural reconstruction is triggered by axonal injury, and that this process is largely dependent on the synthesis of certain proteins, to which GAP-43 is closely associated. As a marker of axonal regeneration, GAP-43 is a nervous tissue-specific cytoplasmic protein highly expressed in neuronal growth cones, regenerated Schwann and glial cells during development, and during axonal regeneration. It is thought to be involved in neural development, neurite elongation and synapse formation $(30,31)$. The first step of axonal regeneration is the formation of the growth cone. Normally, the combination of $\mathrm{G}$ proteins and receptors within growth cones induces growth cone collapse and growth inhibition. GAP-43 is expressed on the surface of growth cones, and its binding to $\mathrm{G}$ proteins induces release of $\mathrm{G}$ proteins from its combination and termination of subsequent inhibitory signaling pathways, which ultimately leads to elongation and regeneration of axons (32). The activated growth cones extend the presynaptic membrane and form synaptic connections resulting in enhanced release of vesicular transmitters and stimulation of various biological effects $(33,34)$. However, the presence of an inhibitory environment in the CNS extremely limits axonal regeneration following SCI. To date, myelin-associated protein Nogo-A has been identified as the most potent inhibitor of neurite growth. The lack of CNS regeneration in adult mammals is largely attributed to the presence of Nogo-A, and its receptor $\mathrm{NgR}(9,35-37)$. Nogo-A has been demonstrated to bind to its specific receptor, $\mathrm{NgR}$, to initiate a signaling cascade resulting in inhibition of neurite growth. Nogo-A is involved in regulating actin cytoskeleton dynamics in local growth cones, inducing retraction of filopodia and lamellipodia, and ultimately stimulating the collapse of growth cones (38). In addition to Nogo-A, two other myelin-associated neurite growth inhibitors, myelin-associated glycoprotein and OMgp, also bind to $\mathrm{NgR}$. NgR knockdown or downregulation may be an effective disinhibitory strategy to promote CNS axon regeneration $(39,40)$.

Axonal regeneration is the outcome of a counterbalance between stimulatory and inhibitory factors. Thus, there are two approaches to encourage regeneration: altering the environment by blocking/neutralizing inhibitors of regeneration and/or altering the intrinsic growth state of the neuron. The results presented in the present study demonstrated that the levels of GAP-43 mRNA and protein were significantly increased in damaged spinal cord tissue. Administration of IL-6 significantly increased the levels of GAP-43 mRNA and protein in damaged spinal cord tissue and upregulation of the GAP-43 mRNA and protein levels in isolated DRG neurons. The present study demonstrated that addition of exogenous IL-6 to the culture medium or by subarachnoid injection resulted in a dose-dependent increase in GAP-43 expression, which is in accordance with a previous investigation performed using an organotypic hippocampal slice culture model (6). Additionally, in the present study, the protein expression levels of Nogo-A and $\mathrm{NgR}$ were significantly increased in the damaged spinal cord tissue, and this increase was downregulated by IL- 6 in the damaged tissue and isolated neurons.

Taken together, the results of the present study suggest that IL-6 promotes axonal regeneration via stimulating the intrinsic growth state of neurons and resisting the extrinsic inhibitory environment. The cellular and molecular mechanisms by which IL- 6 exerts its beneficial effect may be attributed to its upregulation of GAP-43 expression and simultaneous downregulation of Nogo-A and NgR levels. This provides new insights into the mechanisms of the Nogo-A system in axonal regeneration and will aid the development of novel treatment strategies for SCI.

\section{Acknowledgements}

This study was supported by grants from the Chongqing Nature Science Foundation (grant no. CSTC2013jcyjA10079). The authors would also like to thank the editors of the Spandidos Publications - English Language Editing Service, for professional English language editing of this article.

\section{References}

1. Wang KC, Koprivica V, Kim JA, Sivasankaran R, Guo Y, Neve RL and He Z: Oligodendrocyte-myelin glycoprotein is a Nogo receptor ligand that inhibits neurite outgrowth. Nature 417: 941-944, 2002.

2. Filbin MT: Myelin-associated inhibitors of axonal regeneration in the adult mammalian CNS. Nat Rev Neurosci 4: 703-713, 2003.

3. Geoffroy CG and Zheng B: Myelin-associated inhibitors in axonal growth after CNS injury. Curr Opin Neurobiol 27: 31-38, 2014. 
4. Lee JK and Zheng B: Role of myelin-associated inhibitors in axonal repair after spinal cord injury. Exp Neurol 235: 33-42, 2012.

5. Leibinger M, Andreadaki A, Diekmann $\mathrm{H}$ and Fischer D: Neuronal STAT3 activation is essential for CNTF- and inflammatory stimulation-induced CNS axon regeneration. Cell Death Dis 4: e805, 2013.

6. Hakkoum D, Stoppini L and Muller D: Interleukin-6 promotes sprouting and functional recovery in lesioned organotypic hippocampal slice cultures. J Neurochem 100: 747-757, 2007.

7. Chidlow G, Wood JP, Ebneter A and Casson RJ: Interleukin-6 is an efficacious marker of axonal transport disruption during experimental glaucoma and stimulates neuritogenesis in cultured retinal ganglion cells. Neurobiol Dis 48: 568-581, 2012.

8. Wang T, Xiong JQ, Ren XB and Sun W: The role of Nogo-A in neuroregeneration: a review. Brain Res Bull 87: 499-503, 2012.

9. Pernet V and Schwab ME: The role of Nogo-A in axonal plasticity, regrowth and repair. Cell Tissue Res 349: 97-104, 2012.

10. Yu CH, Yhee JY, Kim JH, Im KS, Kim NH, Jung DI, Lee HC, Chon SK and Sur JH: Pro- and anti-inflammatory cytokine expression and histopathological characteristics in canine brain with traumatic brain injury. J Vet Sci 12: 299-301, 2011

11. Okada S, Nakamura M, Mikami Y, Shimazaki T, Mihara M, Ohsugi Y, Iwamoto Y, Yoshizaki K, Kishimoto T, Toyama Y, et al: Blockade of interleukin-6 receptor suppresses reactive astrogliosis and ameliorates functional recovery in experimental spinal cord injury. J Neurosci Res 76: 265-276, 2004.

12. Guerrero AR, Uchida K, Nakajima $H$, Watanabe S, Nakamura M, Johnson WE and Baba $\mathrm{H}$ : Blockade of interleukin- 6 signaling inhibits the classic pathway and promotes an alternative pathway of macrophage activation after spinal cord injury in mice. J Neuroinflammation 9: 40, 2012.

13. Wang XQ, Peng YP, Lu JH, Cao BB and Qiu YH: Neuroprotection of interleukin-6 against NMDA attack and its signal transduction by JAK and MAPK. Neurosci Lett 450: 122-126, 2009.

14. Ou S, Zhao YD, Xiao Z, Wen HZ, Cui J and Ruan HZ: Effect of lappaconitine on neuropathic pain mediated by $\mathrm{P} 2 \mathrm{X}_{3}$ receptor in rat dorsal root ganglion. Neurochem Int 58: 564-573, 2011.

15. Basso DM, Beattie MS and Bresnahan JC: A sensitive and reliable locomotor rating scale for open field testing in rats. $\mathbf{J}$ Neurotrauma 12: 1-21, 1995.

16. Bareyre FM, Haudenschild B and Schwab ME: Long-lasting sprouting and gene expression changes induced by the monoclonal antibody IN-1 in the adult spinal cord. J Neurosci 22: 7097-7110, 2002

17. Matsushita H, Endo S, Kobayashi E, Sakamoto Y, Kobayashi K, Kitaguchi K, Kuroki K, Söderhäll A, Maenaka K, Nakamura A, et al: Differential but competitive binding of Nogo protein and class i major histocompatibility complex (MHCI) to the PIR-B ectodomain provides an inhibition of cells. J Biol Chem 286 : 25739-25747, 2011.

18. Cao Z, Gao Y, Bryson JB, Hou J, Chaudhry N, Siddiq M, Martinez J, Spencer T, Carmel J, Hart RB, et al: The cytokine interleukin-6 is sufficient but not necessary to mimic the peripheral conditioning lesion effect on axonal growth. J Neurosci 26 : $5565-5573,2006$

19. Siddiq MM and Hannila SS: Looking downstream: the role of cyclic AMP-regulated genes in axonal regeneration. Front Mol Neurosci 8: 26, 2015.

20. Hannila SS and Filbin MT: The role of cyclic AMP signaling in promoting axonal regeneration after spinal cord injury. Exp Neurol 209: 321-332, 2008

21. Lau BY, Fogerson SM, Walsh RB and Morgan JR: Cyclic AMP promotes axon regeneration, lesion repair and neuronal survival in lampreys after spinal cord injury. Exp Neurol 250: 31-42, 2013.

22. Peace AG and Shewan DA: New perspectives in cyclic AMP-mediated axon growth and guidance: the emerging epoch of Epac. Brain Res Bull 84: 280-288, 2011.
23. Schumann G, Huell M, Machein U, Hocke G and Fiebich BL: Interleukin- 6 activates signal transducer and activator of transcription and mitogen-activated protein kinase signal transduction pathways and induces de novo protein synthesis in human neuronal cells. J Neurochem 73: 2009-2017, 1999.

24. Pizzi M, Sarnico I, Boroni F, Benarese M, Dreano M, Garotta G, Valerio A and Spano P: Prevention of neuron and oligodendrocyte degeneration by interleukin-6 (IL-6) and IL-6 receptor/IL-6 fusion protein in organotypic hippocampal slices. Mol Cell Neurosci 25: 301-311, 2004

25. Agthong S, Koonam J, Kaewsema A and Chentanez V: Inhibition of MAPK ERK impairs axonal regeneration without an effect on neuronal loss after nerve injury. Neurol Res 31: 1068-1074, 2009.

26. Liu RY and Snider WD: Different signaling pathways mediate regenerative versus developmental sensory axon growth. J Neurosci 21: RC164, 2001.

27. Wiklund P,Ekström PA and Edström A: Mitogen-activated protein kinase inhibition reveals differences in signalling pathways activated by neurotrophin-3 and other growth-stimulating conditions of adult mouse dorsal root ganglia neurons. J Neurosci Res 67: 62-68, 2002.

28. Teng FY and Tang BL: Axonal regeneration in adult CNS neurons - signaling molecules and pathways. J Neurochem 96: 1501-1508, 2006.

29. Hellenbrand DJ, Kaeppler KE, Hwang E, Ehlers ME, Toigo RD, Giesler JD, Vassar-Olsen ER and Hanna A: Basic techniques for long distance axon tracing in the spinal cord. Microsc Res Tech 76: 1240-1249, 2013.

30. Grasselli G, Mandolesi G, Strata P and Cesare P: Impaired sprouting and axonal atrophy in cerebellar climbing fibres following in vivo silencing of the growth-associated protein GAP-43. PLoS One 6: e20791, 2011.

31. Yuan Q, Hu B, Su H, So KF, Lin Z and Wu W: GAP-43 expression correlates with spinal motoneuron regeneration following root avulsion. J Brachial Plex Peripher Nerve Inj 4: 18, 2009.

32. Strittmatter SM: GAP-43 as a modulator of G protein transduction in the growth cone. Perspect Dev Neurobiol 1: 13-19, 1992

33. Fenrich KK, Skelton N, MacDermid VE, Meehan CF, Armstrong S, Neuber-Hess MS and Rose PK: Axonal regeneration and development of de novo axons from distal dendrites of adult feline commissural interneurons after a proximal axotomy. J Comp Neurol 502: 1079-1097, 2007.

34. Denny JB: Molecular mechanisms, biological actions, and neuropharmacology of the growth-associated protein GAP-43. Curr Neuropharmacol 4: 293-304, 2006.

35. Huo Y, Yin XL, Ji SX, Zou H, Lang M, Zheng Z, Cai XF, Liu W, Chen CL, Zhou YG, et al: Amino-Nogo inhibits optic nerve regeneration and functional recovery via the integrin $\alpha \mathrm{v}$ signaling pathway in rats. Cell Physiol Biochem 35: 616-626, 2015.

36. Schwab ME and Strittmatter SM: Nogo limits neural plasticity and recovery from injury. Curr Opin Neurobiol 27: 53-60, 2014.

37. Kempf A and Schwab ME: Nogo-A represses anatomical and synaptic plasticity in the central nervous system. Physiology (Bethesda) 28: 151-163, 2013.

38. Wälchli T, Pernet V, Weinmann O, Shiu JY, Guzik-Kornacka A, Decrey G, Yüksel D, Schneider H, Vogel J, Ingber DE, et al: Nogo-A is a negative regulator of CNS angiogenesis. Proc Natl Acad Sci USA 110: E1943-E1952, 2013.

39. Ahmed Z, Dent RG, Suggate EL, Barrett LB, Seabright RJ, Berry $M$ and Logan A: Disinhibition of neurotrophin-induced dorsal root ganglion cell neurite outgrowth on CNS myelin by siRNA-mediated knockdown of NgR, p75 ${ }^{\text {NTR }}$ and Rho-A. Mol Cell Neurosci 28: 509-523, 2005.

40. Wang $\mathrm{T}$, Wang $\mathrm{J}$, Yin $\mathrm{C}$, Liu R, Zhang JH and Qin X: Down-regulation of Nogo receptor promotes functional recovery by enhancing axonal connectivity after experimental stroke in rats. Brain Res 1360: 147-158, 2010. 